\title{
A miniaturized ommatid beetle in mid-Cretaceous Burmese amber (Coleoptera: Archostemata: Ommatidae)
}

\author{
Yan-Da Lii ${ }^{1,2,5}$; Shûhei Yamamoto ${ }^{3,6}$; Di-Ying Huang ${ }^{1,7}$ \& Chen-Yang Cai ${ }^{1,4,8}$ \\ 1 State Key Laboratory of Palaeobiology and Stratigraphy, Nanjing Institute of Geology and Palaeontology, \\ and Center for Excellence in Life and Palaeoenvironment, Chinese Academy of Sciences, Nanjing, China. \\ ${ }^{2}$ School of Life Sciences, Peking University, Beijing, China. \\ ${ }^{3}$ Hokkaido University Museum, Sapporo, Japan. \\ ${ }^{4}$ School of Earth Sciences, University of Bristol, Bristol, United Kingdom. \\ ${ }^{5}$ ORCID: http://orcid.org/0000-0002-9439-202X. E-mail: ydli@pku.edu.cn \\ ${ }^{6}$ ORCID: http://orcid.org/0000-0002-4162-8457. E-mail: s.yamamot0.64@gmail.com \\ 7 ORCID: http://orcid.org/0000-0002-5637-4867. E-mail: dyhuang@nigpas.ac.cn \\ ${ }^{8}$ ORCID: http://orcid.org/0000-0002-9283-8323. E-mail: cycai@nigpas.ac.cn (corresponding author)
}

\begin{abstract}
Recent findings of ommatids from mid-Cretaceous Burmese amber have greatly increased our knowledge on the Mesozoic diversity of 0 mmatidae. Here, we report the first distinctly miniaturized ommatid species, Miniomma chenkuni gen. et sp. nov., entombed in mid-Cretaceous amber from northern Myanmar. This new fossil species is characterized by its small body size (less than $2 \mathrm{~mm}$ long) and subglobular metacoxae. Our discovery of miniaturization in extinct Ommatidae suggests a high ecological diversity of this family in the Mesozoic.
\end{abstract}

Key-Words. Archostemata; Ommatidae; Miniomma; Miniaturization; Burmese amber.

\section{INTRODUCTION}

Ommatidae is a small family in the beetle suborder Archostemata, with only three extant genera, Omma Newman and Beutelius Escalona et al. in Australia, and Tetraphalerus Waterhouse in South America (Hörnschemeyer \& Beutel, 2016; Lawrence \& Escalona, 2019; Escalona et al., 2020). Fossil records have revealed that ommatids had a much higher diversity during the Mesozoic, as well as wider distribution (Cai \& Huang, 2017; Kirejtshuk, 2020). Morphologically, Ommatidae is most similar to the family Cupedidae. Recent molecular phylogenetic analyses, however, have revealed a closer affinity between Ommatidae and Micromalthidae (McKenna et al., 2015, 2019). Historically, Mesozoic ommatids are only represented by compression or impression fossils, in which detailed structures are not well preserved. Recently, various exquisitely preserved ommatids have been described from mid-Cretaceous Burmese amber, including at least 21 species in 11 genera (generic assignment according to original authors) (Ross, 2019, 2020; Jarzembowski et al., 2020; Kirejtshuk, 2020). These amber inclusions with astonishingly fine details greatly enhanced our understanding of the diversity and disparity of Mesozoic ommatids.

Miniaturization, or the evolution towards extremely small body size, is a commonly found phenomenon in animals (Hanken \& Wake, 1993), and insects in particular (Polilov, 2016; Minelli \& Fusco, 2019). The upper size limit for microinsects have been somewhat arbitrarily determined to $2 \mathrm{~mm}$, partly based on the threshold of pumilistic degeneration (Polilov, 2016). Most of these microinsects belong to Coleoptera (beetles) or Hymenoptera (ants, bees and wasps) (Polilov, 2016). Even though miniaturization is quite common in beetles, such a phenomenon was previously unknown in any extant or fossil representatives in the beetle family Ommatidae. Here, we report the first miniaturized member of Ommatidae from Burmese amber, which not only increases our knowledge on the morphological diversity of this family, but also points to a high ecological diversity of Mesozoic ommatids.

\section{MATERIAL AND METHODS}

The Burmese amber specimens studied here were derived from amber mines near Noije Bum 
Village $\left(26^{\circ} 20^{\prime} \mathrm{N}, 96^{\circ} 36^{\prime} \mathrm{E}\right)$, Hukawng Valley, Kachin State, northern Myanmar. The holotype is deposited in the Nanjing Institute of Geology and Palaeontology (NIGP), Chinese Academy of Sciences, Nanjing, China. The paratypes are deposited in Oregon State Arthropod Collection (OSAC), Oregon State University, Corvallis, OR, United States of America. The amber pieces were trimmed with a small table saw, ground with emery papers of different grain sizes, and finally polished with polishing powder.

Photographs under incident light were taken with a Zeiss Discovery V20 stereo microscope. Widefield fluorescence images were captured with a Zeiss Axio Imager 2 light microscope combined with a fluorescence imaging system. Confocal images were obtained with a Zeiss LSM710 confocal laser scanning microscope. Images under incident light and widefield fluorescence were stacked in Helicon Focus 7.0.2 or Zerene Stacker 1.04. Confocal images were manually stacked in Adobe Photoshop CC. The holotype was also imaged using high-resolution X-ray microtomography (Zeiss Xradia 520 Versa) at the micro-CT laboratory of NIGP. Based on the comparatively small size of the fossil specimen, a CCD-based $4 \times$ objective was used, providing isotropic voxel sizes of $2.1437 \mu \mathrm{m}$ with the help of geometric magnification. During the scanning, the acceleration voltage for the X-ray source was $40 \mathrm{kV}$. To improve signal-to-noise ratio, 3,001 projections over $360^{\circ}$ were collected, and the exposure time for each projection was $4 \mathrm{~s}$. The tomographic data were analyzed using VGStudio MAX 3.0. Images were further processed in Adobe Photoshop CC to enhance contrast.

\section{RESULTS}

\section{Systematic Paleontology}

\section{Order Coleoptera Linnaeus, 1758 Suborder Archostemata Kolbe, 1908 Family Ommatidae Sharp \& Muir, 1912 Genus Miniomma Li, Yamamoto \& Cai gen. nov.}

Type species: Miniomma chenkuni Li, Yamamoto \& Cai sp. nov.

Diagnosis: Body minute. Head moderately elongate, without distinct protuberances; compound eyes not protruding; antennae subfiliform; antennomere 3 slightly longer than 4; antennomere 11 nearly twice as long as 10; antennal grooves absent. Pronotal disc with a shallow medial groove; propleura fused with prosternum; procoxae contiguous; metacoxae subglobular, not extending laterally. Elytra non-serrate, with very narrow epipleura, and with indistinct longitudinal ridges (primary veins). Abdominal ventrites abutting; ventrite 5 slightly longer than penultimate one, with broadly gently arcuate posterior margin.

Etymology: The generic name is derived from the English "mini-", meaning small, and the generic name
"Omma", the type genus of Ommatidae. The name is neuter in gender.

\section{Miniomma chenkuni Li, Yamamoto \& Cai sp. nov.} (Figs. 1-4)

Material: Holotype, NIGP173375, sex unknown. Paratypes, OSAC_0002900274,OSAC_0002900275,OSAC_0002900276 and OSAC_0002900277, sex unknown. The specimens OSAC_0002900274-6 are in one piece of amber.

Locality and horizon: Amber mine located near Noije Bum Village, Tanai Township, Myitkyina District, Kachin State, Myanmar; unnamed horizon, mid-Cretaceous, Upper Albian to Lower Cenomanian (Mao et al., 2018).

Diagnosis: As for the genus.

Description: Body minute, 1.2-2.0 mm long, 0.4-0.7 mm wide, tuberculate, with thin setae.

Head (Figs. 3D, 4A-B) prognathous, moderately elongate, constricted posteriorly to form a neck; dorsal surface with Y-shaped depression (see Kirejtshuk et al., 2016), but without distinct protuberances. Temples moderately long, not prominent. Compound eyes entire and not protruding, finely facetted, without interfacetal setae. Antennal insertions lateral. Antennal grooves absent. Antenna extending beyond anterior prothoracic margin, but not reaching posterior prothoracic margin, 11-segmented and subfiliform, with thin hairs; antennomere 3 slightly longer than 4; antennomere 11 nearly twice as long as 10. Labrum transverse, with apex slightly concave. Mandible with vertically aligned teeth. Maxillary and labial palps relatively short, not reaching mandibular apex when anteriorly directed. Prementum subtrapezoidal. Gular sutures invisible.

Pronotal disc (Fig. 4A) longer than wide, with a shallow medial groove; anterior corners rounded. Prosternum (Fig. 4B) in front of coxae moderately long, probably fused with propleura. Prosternal process incomplete, apically acute. Procoxal cavities contiguous. Elytra (Figs. 3F, 4C) 1.7 times as long as wide combined, with rows of window punctures, probably without maculae; longitudinal ridges (primary veins) weakly raised.

Procoxae (Fig. 4B) subglobular. Metacoxae (Figs. 3E, 4D) subglobular, not extending laterally. Femora stout. Tibiae thinner, without well-developed tibial spurs. Tarsi five-segmented; tarsomeres simple, not bilobed; tarsomeres 1-4 subequal in length; tarsomere 5 more than twice as long as tarsomere 4; pretarsal claws simple.

Abdomen with five coplanar ventrites, separated by wide grooves; ventrite 1 longer than others; ventrite 5 slightly longer than penultimate one, with broadly gently arcuate posterior margin.

Etymology: The species is named after Dr. Chen-Kun Jiang, a young evolutionary botanist, who helped the first author enormously on his previous research project. 

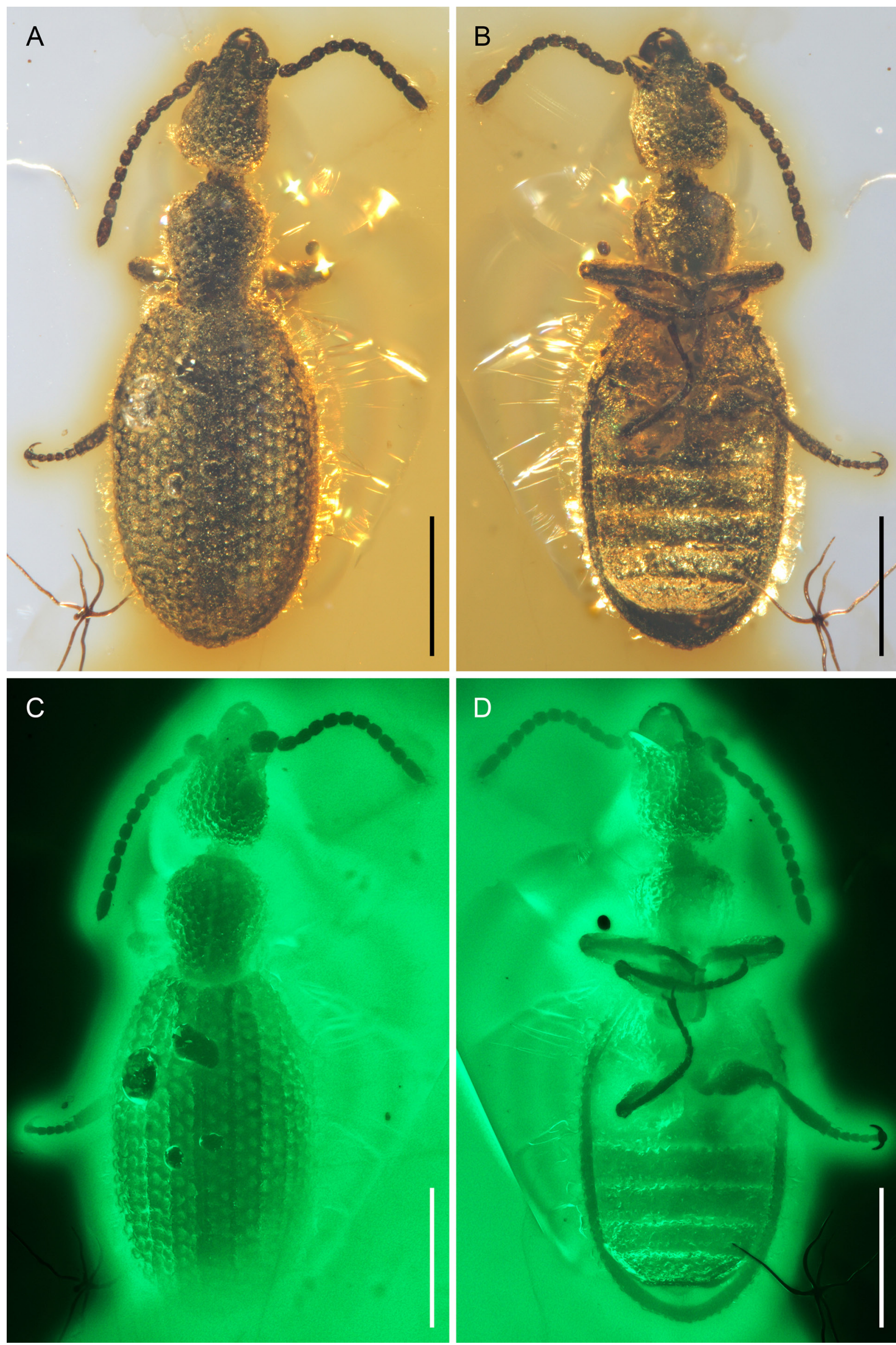

Figure 1. General habitus of Miniomma chenkuni gen. et sp. nov., holotype, NIGP173375. (A) Dorsal view, under incident light. (B) Ventral view, under incident light. (C) Dorsal view, under widefield fluorescence. (D) Ventral view, under widefield fluorescence. Scale bars: $400 \mu \mathrm{m}$. 

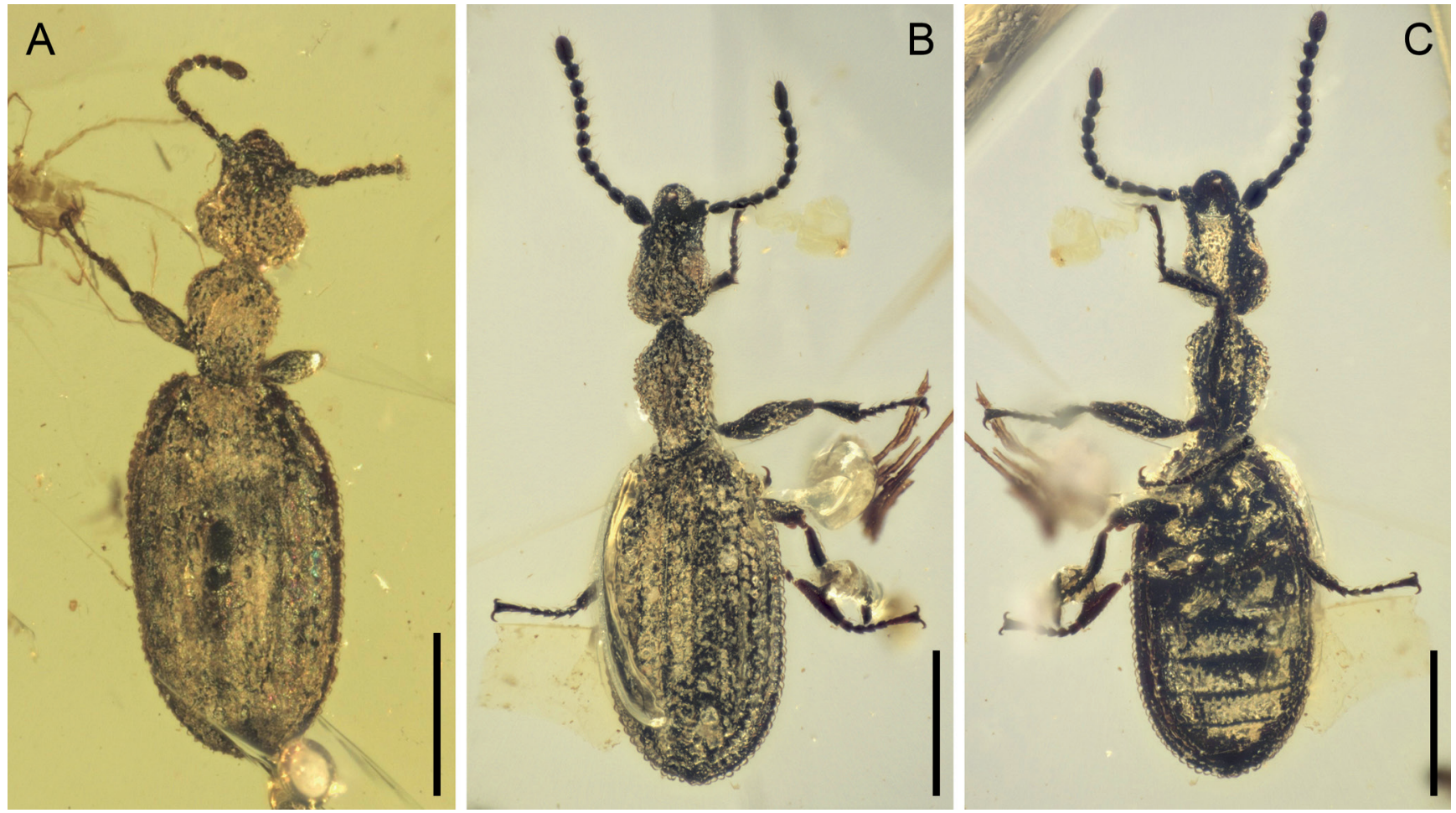

Figure 2. General habitus of Miniomma chenkuni gen. et sp. nov., paratypes, under incident light. (A) OSAC_0002900274, dorsal view. (B) 0SAC_0002900277, dorsal view. (C) OSAC_0002900277, ventral view. Scale bars: $500 \mu \mathrm{m}$ in (A), $300 \mu \mathrm{m}$ in (B-C).

\section{DISCUSSION}

While there are only three genera and seven species in extant Ommatidae, this family was much more diverse in the Mesozoic (e.g., Kirejtshuk, 2020). Recent findings of ommatids from Burmese amber have revealed a set of intriguing characters previously unknown in Ommatidae (e.g., Jarzembowski \& Wang, 2016; Jarzembowski et al., 2018, 2019). Even though the fossils have greatly enriched our knowledge on the morphological diversity of Ommatidae, there are nevertheless some conserved characters within Ommatidae. All extant ommatids are characterized by mandibles with three vertically arranged teeth (Hörnschemeyer, 2009; fig. 4 in Beutel et al., 2008; fig. 18 in Escalona et al., 2020). Tan et al. (2012) claimed that the cutting edge of mandible is horizontal in most fossil ommatids. However, based on our observation of amber inclusions, the mandibles are equipped with vertically arranged teeth in all fossil ommatid genera from Burmese amber, except for Notocupes Ponomarenko. The cutting edge in $N$. denticollis Jiang et al. specimen we examined is not well exposed, so better preserved specimens may be required to clarify the condition in Notocupes. Our observation nevertheless confirms that vertically arranged mandibular teeth are ubiquitous in fossil ommatids. The horizontal mandibular cutting edge as suggested in Tan et al. (2012) was probably a taphonomic artefact, as characters are often compressed and deformed in compression fossils. The mandibles of Miniomma also clearly possess vertically arranged apical teeth. Short prosternal process and contiguous procoxae are another conserved feature for om- matids. In Ommatidae, only Stegocoleus Jarzembowski \& Wang is known to have separate procoxae. The separate procoxae probably evolved convergently in Cupedidae and Stegocoleus. Similar to most ommatids, the procoxae are also contiguous in Miniomma. Besides, the tarsomeres of Miniomma are all simple, and the abdominal ventrites are coplanar, which are also characteristic of Ommatidae. Therefore Miniomma is closely related to other ommatids, and should be placed in the family Ommatidae.

As shown in Escalona et al. (2020), the lengths of maxillary and labial palps serve as useful characters in distinguishing genera in Ommatidae. The maxillary and labial palps of Beutelius are quite long, clearly reaching beyond eyes when extended posteriorly (Escalona et al., 2020). The palps are distinctly shorter in both Omma and Tetraphalerus, but the maxillary palps can reach at least the apex of mandibles when anteriorly directed. In some fossil ommatids (e.g., Clessidromma Jarzembowski et al. and Paraodontomma Yamamoto) the maxillary and labial palps can be relatively reduced, far from reaching the mandibular apex. It seems that the maxillary and labial palps are also relatively short in Miniomma, not reaching mandibular apex when anteriorly directed. The propleura are partly or completely fused to prosternum in Omma and Beutelius (Escalona et al., 2020), while separate propleura can be clearly identified in Tetraphalerus (Friedrich et al., 2009), as well as some fossil ommatids including Lepidomma Jarzembowski et al. Similar to extant Omma, the prosternum appears to be completely fused to the propleura in Miniomma. The subglobular metacoxae of Miniomma are quite peculiar 
in Archostemata. In most archostematans, the metacoxae are strongly transverse and extend laterally to meet sides of body (Lawrence et al., 2011). Another minute archostematan, Micromalthus LeConte, is also known to have metacoxae not reaching sides of body (Lawrence et al., 2011), though a short lateral extension is present (image Abd-v in Hörnschemeyer, 2017). In contrast, no lateral extension seems to be existed in Miniomma at all.

In terms of body size, extant Omma and Beutelius range in length from $6 \mathrm{~mm}$ to $26 \mathrm{~mm}$ (Escalona et al., 2020). Extant Tetraphalerus range in body length from $11 \mathrm{~mm}$ to $15 \mathrm{~mm}$ (Ponomarenko, 1969). Fossil ommatids have a wider range of sizes. For example, Bukhkalius lindae (Jarzembowski et al.) from mid-Cretaceous Burmese amber have a body length of $4.1 \mathrm{~mm}$ (Jarzembowski et al., 2017). However, none of these ommatids meet the criterion of microinsects, i.e., having a body length less than $2 \mathrm{~mm}$. As such, Miniomma is the first known example of remarkable and unexpected miniaturization in ommatids. While most studies on insect miniaturization were focused on morphological perspectives, the ecological significance of miniaturization is relatively poorly known. Possible benefits of min-
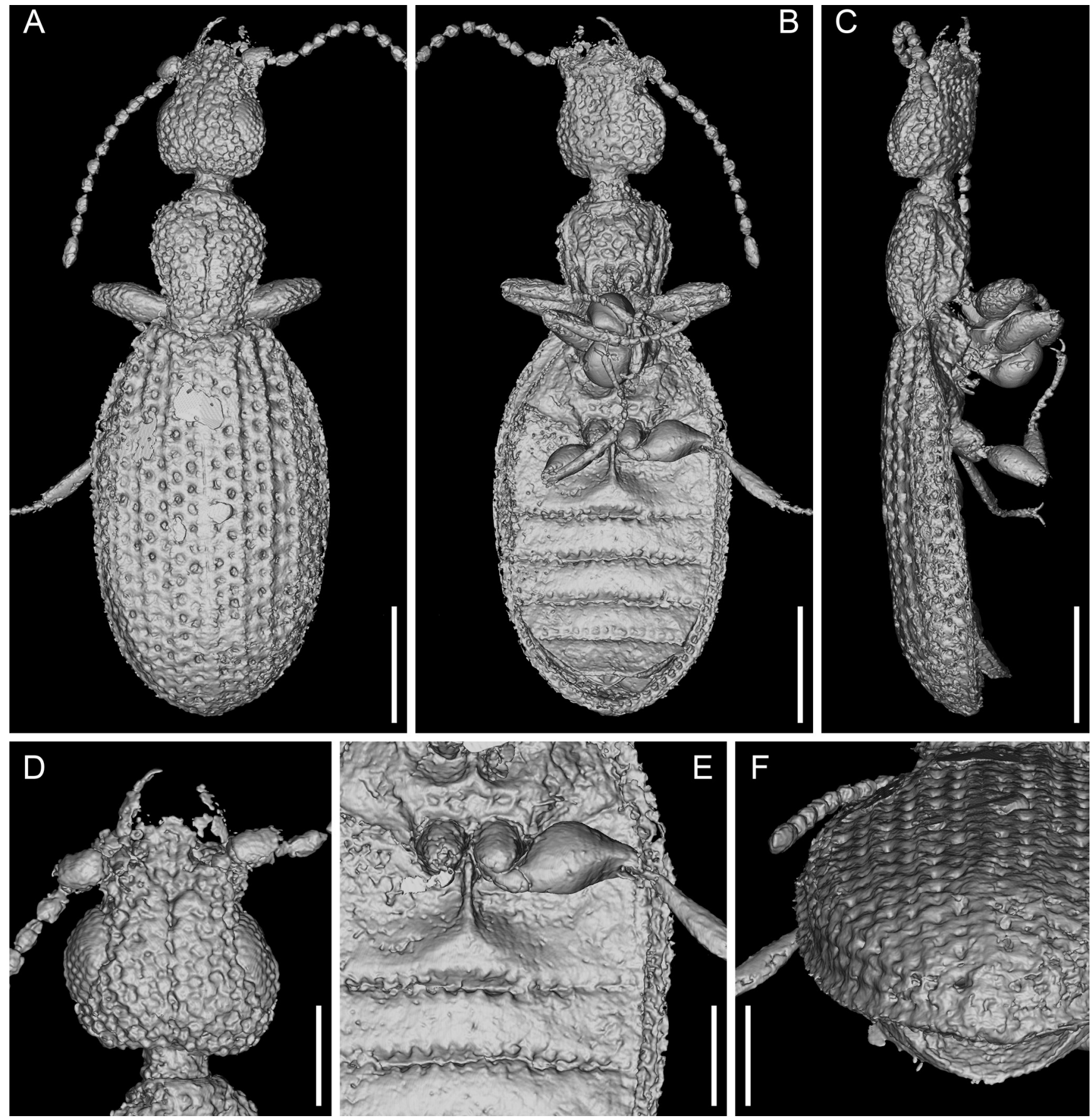

Figure 3. X-ray microtomographic reconstruction of Miniomma chenkuni gen. et sp. nov., holotype, NIGP173375. (A) Habitus, dorsal view. (B) Habitus, ventral view. (C) Habitus, lateral view. (D) Head, dorsal view. (E) Hind legs and anterior portion of abdomen, with right hind leg partly removed, ventral view. (F) Left elytron, posterodorsal view. Scale bars: $300 \mu \mathrm{m}$ in (A-C), $150 \mu \mathrm{m}$ in (D-F). 

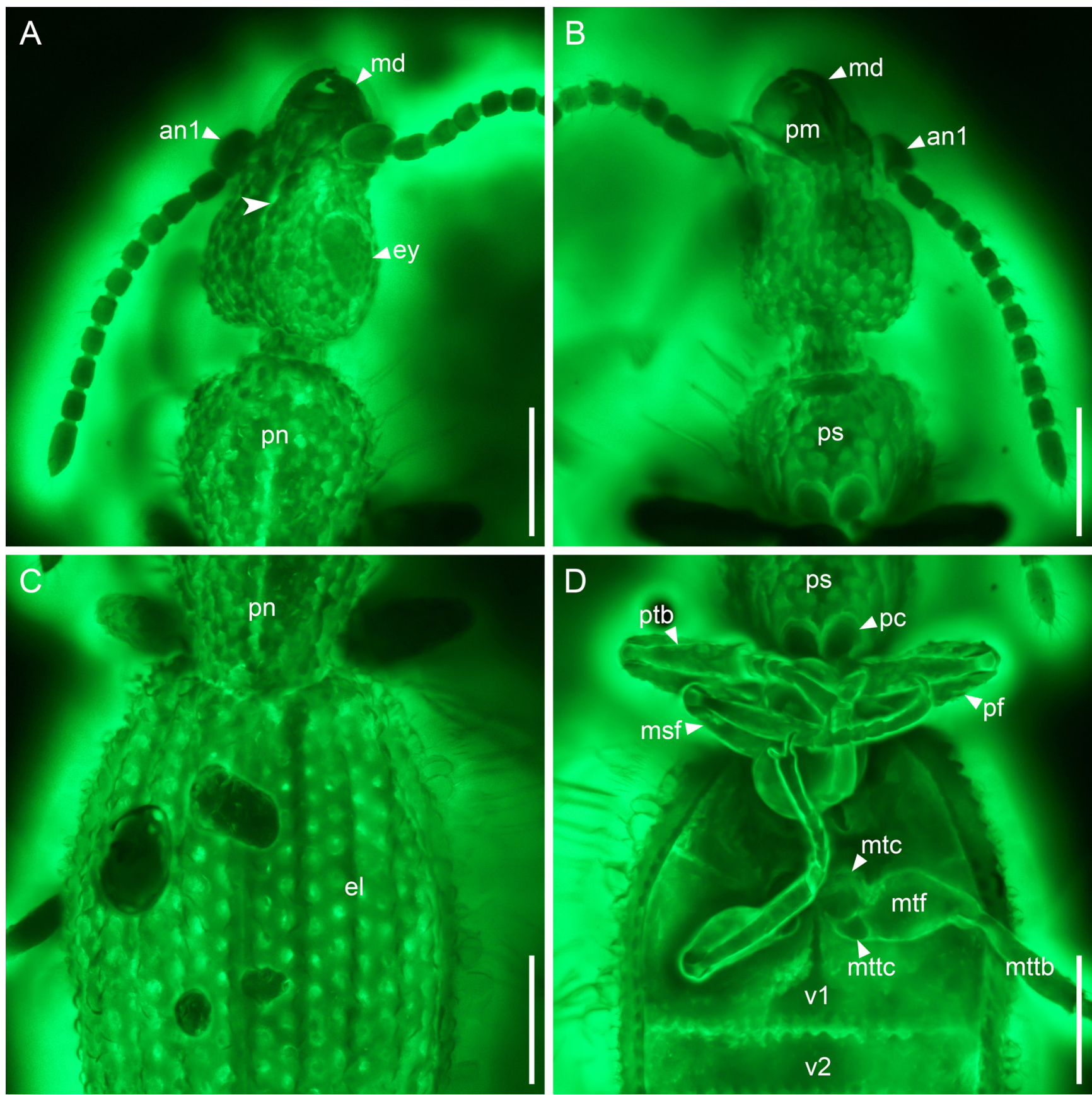

Figure 4. Details of Miniomma chenkuni gen. et sp. nov., holotype, NIGP173375, under confocal microscopy. (A) Head and anterior portion of prothorax, dorsal view, with arrowhead showing the Y-shaped depression. (B) Head and anterior portion of prothorax, ventral view. (C) Posterior portion of prothorax and anterior portion of

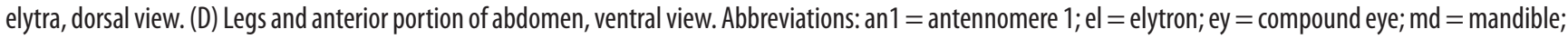
$\mathrm{msf}=$ mesofemur; $\mathrm{mtc}=$ metacoxa; $\mathrm{mtf}=$ metafemur; $\mathrm{mttb}=$ metatibia; $\mathrm{mttc}=$ metatrochanter $; \mathrm{pc}=$ procoxa; $\mathrm{pf}=$ profemur; $\mathrm{pn}=$ pronotum; $\mathrm{pm}=\mathrm{prementum} ;$ $\mathrm{ps}=$ prosternum; $\mathrm{ptb}=$ protibia; $\mathrm{v1-2}=$ ventrites $1-2$. Scale bars: $200 \mu \mathrm{m}$.

iaturization may include avoiding predators, switching food sources, utilizing physically smaller niches, and earlier reproduction (Zimkus et al., 2012). Though we are unable to identify the exact ecological driving force accounting for miniaturization of Miniomma, the miniaturized body size nevertheless certainly played an important role in developing its new ecological niche. Ommatidae in Mesozoic were not only more diversified than in present day in morphology (e.g., Kirejtshuk, 2020), but also probably occupied much more diverse ecological habitats.

\section{DATA AVAILABILITY}

The original series of confocal slices and micro-CT slices are available on Zenodo repository (http://doi. org/10.5281/zenodo.3994920).

\section{AUTHOR'S CONTRIBUTIONS}

C.-Y.C. and Y.-D.L. conceived the study.Y.-D.L. acquired and processed the photomicrographs. Y.-D.L. and C.-Y.C. 
processed the micro-CT data. Y.-D.L. and C.-Y.C. drafted the manuscript, to which S.Y. contributed. All authors commented on the manuscript and gave final approval for publication.

\section{ACKNOWLEDGMENTS}

We are grateful to David R. Maddison for providing high-quality photos of the paratypes of Miniomma chenkuni, Su-Ping Wu for technical help in micro-CT reconstruction, Yan Fang for technical help in confocal imaging, Dao-Jun Yuan for help in inspecting the type specimens deposited at NIGP, and Ye Liu for arranging a loan of the holotype of Notocupes denticollis. This work was supported by the Strategic Priority Research Program of the Chinese Academy of Sciences (XDB18000000, XDB26000000), the National Natural Science Foundation of China (41688103), the Second Tibetan Plateau Scientific Expedition and Research (2019QZKK0706), and the Grant-in-Aid for JSPS Fellows (20J00159) given to S.Y. from the Japan Society for the Promotion of Science (JSPS).

\section{REFERENCES}

Beutel, R.G.; Ge, S.-Q. \& Hörnschemeyer, T. 2008. On the head morphology of Tetraphalerus, the phylogeny of Archostemata and the basal branching events in Coleoptera. Cladistics, 24(3): 270-298.

Cai, C. \& Huang, D. 2017. Omma daxishanense sp. nov., a fossil representative of an extant Australian endemic genus recorded from the Late Jurassic of China (Coleoptera: Ommatidae). Alcheringa, 41:277-283. D0I

Escalona, H.E.; Lawrence, J.F. \& Ślipiński, A. 2020. The extant species of the genus Omma Newman and description of Beutelius gen. nov. (Coleoptera: Archostemata: Ommatidae: Ommatinae). Zootaxa, 4728: 547-574.

Friedrich, F.; Farrell, B.D. \& Beutel, R.G. 2009. The thoracic morphology of Archostemata and the relationships of the extant suborders of Coleoptera (Hexapoda). Cladistics, 25: 1-37.

Hanken, J. \& Wake, D. 1993. Miniaturization of body size: organismal consequences and evolutionary significance. Annual Review of Ecology and Systematics, 24: 501-519.

Hörnschemeyer, T. 2009. The species-level phylogeny of archostematan beetles-where do Micromalthus debilis and Crowsoniella relicta belong? Systematic Entomology, 34: 533-558. D01

Hörnschemeyer, T. 2017. Micromalthus debilis (Coleoptera: Archostemata), male, SEM images. Zenodo. DOI

Hörnschemeyer, T. \& Beutel, R.G. 2016. Ommatidae Sharp \& Muir, 1912. In: Beutel, R.G. \& Leschen, R.A.B. (Eds.). Handbook of Zoology, Arthropoda: Insecta, Coleoptera, beetles, Vol. 1: morphology and systematics (Archostemata, Adephaga, Myxophaga, Polyphaga partim). 2.ed. Berlin, Walter de Gruyter. p. 52-56.

Jarzembowski, E.A. \& Wang, B. 2016. An unusual basal beetle from Myanmar (Coleoptera: Archostemata). Alcheringa, 40: 297-302. D0l

Jarzembowski, E.A.; Wang, B. \& Zheng, D. 2017. Another amber first: A tiny tetraphalerin beetle (Coleoptera: Archostemata) in Myanmar birmite. Cretaceous Research, 78: 84-88.
Jarzembowski, E.A.; Wang, B. \& Zheng, D. 2018. A slender new archaic beetle in Burmese amber (Coleoptera: Archostemata). Alcheringa, 42: 110-114. DOI

Jarzembowski, E.A.; Wang, B. \& Zheng, D. 2019. A new scaly archaic beetle (Coleoptera: Archostemata) from mid-Cretaceous Burmese amber. Cretaceous Research, 99: 315-320.

Jarzembowski, E.A.; Wang, B. \& Zheng, D. 2020. An archaic-beetle 'Jaws' from mid-Cretaceous Burmese amber (Coleoptera: Archostemata). Proceedings of the Geologists' Association, 131: 155-159.

Kirejtshuk, A.G. 2020. Taxonomic review of fossil coleopterous families (Insecta, Coleoptera). Suborder Archostemata: superfamilies Coleopseoidea and Cupedoidea. Geosciences, 10: 73. D01

Kirejtshuk, A.G.; Nel, A. \& Kirejtshuk, P.A. 2016. Taxonomy of the reticulate beetles of the subfamily Cupedinae (Coleoptera: Archostemata), with a review of the historical development. Invertebrate Zoology, 13: 61-190. DOI

Lawrence, J.F. \& Escalona, H.E. 2019. Ommatidae Sharp \& Muir, 1912. In: Ślipiński, S.A. \& Lawrence, J.F. (Eds.). Australian Beetles. Vol. 2. Archostemata, Myxophaga, Adephaga, Polyphaga (part). New South Wales, CSIRO Publishing. p. 4-7.

Lawrence, J.F.; Ślipiński, A.; Seago, A.E.; Thayer, M.K.; Newton, A.F. \& Marvaldi, A.E. 2011. Phylogeny of the Coleoptera based on morphological characters of adults and larvae. Annales Zoologici, 61: 1-217. DOI

Mao, Y.; Liang, K.; Su, Y.; Li, J.; Rao, X.; Zhang, H.; Xia, F.; Fu, Y.; Cai, C. \& Huang, D. 2018. Various amber ground marine animals on Burmese amber with discussions on its age. Palaeoentomology, 1:91-103. DOI

McKenna, D.D.; Shin, S.; Ahrens, D.; Balke, M.; Beza-Beza, C.; Clarke, D.J.; Donath, A.; Escalona, H.E.; Friedrich, F.; Letsch, H.; Liu, S.; Maddison, D.; Mayer, C.; Misof, B.; Murin, P.J.; Niehuis, 0.; Peters, R.S.; Podsiadlowski, L.; Pohl, H.; Scully, E.D.; Yan, E.V.; Zhou, X.; Ślipiński, A. \& Beutel, R.G. 2019. The evolution and genomic basis of beetle diversity. Proceedings of the National Academy of Sciences of the United States of America, 116(49): 24729-24737. DOI

McKenna, D.D.; Wild, A.L.; Kanda, K.; Bellamy, C.L.; Beutel, R.G.; Caterino, M.S.; Farnum, C.W.; Hawks, D.C.; Ivie, M.A.; Jameson, M.L.; Leschen, R.A.B, Marvaldi, A.E.; McHugh, J.V.; Newton, A.F.; Robertson, J.A.; Thayer, M.K.; Whiting, M.F.; Lawrence, J.F.; Ślipiński, A.; Maddison, D.R. \& Farrell, B.D. 2015. The beetle tree of life reveals that Coleoptera survived endPermian mass extinction to diversify during the Cretaceous terrestrial revolution. Systematic Entomology, 40(4): 835-880.

Minelli, A. \& Fusco, G. 2019. No limits: Breaking constraints in insect miniaturization. Arthropod Structure and Development, 48: 4-11. D01

Polilov, A.A. 2016. Introduction. In: At the size limit - Effects of miniaturization in insects. Arthropod Structure and Development. Cham, Springer International Publishing. Cap. 1, p. 1-8.

Ponomarenko, A.G. 1969. [Historical development of archostomatan beetles]. Trudy Paleontologicheskogo Instituta, 125: 1-240. [in Russian]

Ross, A.J. 2019. Burmese (Myanmar) amber checklist and bibliography 2018. Palaeoentomology, 2: 22-84. D0I

Ross, A.J. 2020. Supplement to the Burmese (Myanmar) amber checklist and bibliography, 2019. Palaeoentomology, 3: 103-118. D0I

Tan, J.; Wang, Y.; Ren, D. \& Yang, X. 2012. New fossil species of ommatids (Coleoptera: Archostemata) from the Middle Mesozoic of China illuminating the phylogeny of Ommatidae. BMCEvolutionary Biology, 12: 113. D01

Zimkus, B.M.; Lawson, L.; Loader, S.P. \& Hanken, J. 2012. Terrestrialization, miniaturization and rates of diversification in African puddle frogs (Anura: Phrynobatrachidae). PLOS ONE, 7: e35118. DOI 